\title{
Processo de deSENVOLVIMENTO do PROdUTO: APLiCAÇÃo de FERRAMENTAS NA TRANSFORMAÇÃO DE UM BRINQUEDO LÚDICO, FUNCIONAL E INCLUSIVO
}

Dana Mendes Vargas (ana.vargas@acad.pucrs.br) - Pontifícia Universidade Católica do Rio Grande do Sul, PUC-RS.

Patrícia Flores Magnago (patricia.magnago@pucrs.br) - Pontifícia Universidade Católica do Rio Grande do Sul, PUC-RS.

\section{RESUMO}

O presente trabalho tem como objetivo geral a aplicação de ferramentas do Processo de Desenvolvimento do Produto, transformando a ideia de um brinquedo organizador artesanal em um produto lúdico, funcional e inclusivo. Fez-se uso do método tradicional de desenvolvimento de produto, com as fases e ferramentas baseadas em Rozenfeld et al (2006). O artigo trabalha o projeto informacional - com questionário aplicado e análise de um modelo de brinquedo inicial - o projeto conceitual - com a criação de Diagrama FAST, Matriz de Mudge, Matriz Morfológica e Matriz de Pugh - e, o projeto detalhado - com o desenvolvimento de um protótipo, Fault Tree Analisys e coleta de feedback. Ressalta-se a relevância do PDP na geração de ideias e proposição de melhorias, em específico na criação de um protótipo virtual de um polvo com oito tentáculos e encaixe de silicone aos lápis-de-cor, compondo um produto de silicone e fios elásticos, com uma ventosa central, sendo o produto capaz de contemplar a função principal e as quatro secundárias.

Palavras chave: Processo de Desenvolvimento de Produto; Engenharia do Produto; brinquedos; inclusão; Design Social; Infantil. 


\section{INTRODUÇÃO}

O estudo do chamado Design Social iniciou-se na década de 70, tendo como objetivo melhorar o bem-estar humano e gerar criações com impactos reais no mundo (SILVA et al., 2012), de forma que, o Design Inclusivo também ganhou destaque, criando produtos que maximizem a integração de públicos com características limitadoras (CRUZ, 2010). O desenvolvimento do produto passa a ter, desde então, a necessidade de atender as demandas de uma sociedade globalizada e acelerada, seguindo o avanço tecnológico e o perfil consumidor.

A Engenharia do Produto se refere ao conjunto de ferramentas e processos de projeto, planejamento, organização, decisão e execução, e envolve desde a concepção até o lançamento (BAXTER, 2011). O desenvolvimento de produto trata da criatividade de maneira ampla e estruturada, de forma a gerar ideias com potencial funcional (ROZENFELD et al., 2006). As etapas são essenciais para concepção e detalhamento de produtos livre de falhas, englobando trabalhos de qualquer segmento, incluindo o ramo da criação de brinquedos, na transformação de uma ideia em um potencial produto.

Famílias buscam utilizar produtos que integrem diversão e praticidade, para otimizar o tempo e as experiências vividas. Crianças, em especial, demandam a utilização de brinquedos lúdicos e atrativos, que também não gerem bagunça e trabalho aos pais. Com um brinquedo, a criança irá ter a oportunidade de desenvolver competências e habilidades fundamentais (SILVA, 2013). Uma destas competências tem relação ao ato de desenhar, momento em que a criança se expressa e se desenvolve cognitivamente, além de auxiliar no processo de aprendizagem e comunicação (TENUTA, 2005).

O setor de brinquedos encerrou 2018 com 7,5\% de crescimento em relação ao ano anterior (ABRIN, 2019). Além disto, durante o período da pandemia do Corona Vírus, diversas famílias tiveram as suas realidades adaptadas, crianças têm passado um período muito maior de tempo dentro de casa, e as suas atividades escolares tem sido trabalhadas de maneira remota, fato este que culminou em um número de queda nas matrículas das escolas, chegando à 470.545 matrículas a menos em comparação ao mesmo período de 2019 no ensino básico nacional (INEP, 2020). Com a demanda por atividades que entretenham as crianças em casa e em decorrência da queda de importações chinesas, as fábricas de brinquedos brasileiras apresentaram números positivos referentes à novas contratações de funcionários durante o período, visando um ano positivo para o setor em relação à 2019 (ABRIN, 2020).

Crianças portadoras de necessidades especiais, com transtornos como TDA (Transtorno de Déficit de Atenção) ou distúrbios da visão, como o daltonismo, carecem de brinquedos que 
sejam de fácil adaptação e apresentem soluções simples para o auxílio nas tarefas diárias, bem como promovam o desenvolvimento cognitivo (PEREIRA et al., 2014). A bagunça gerada por diversos lápis, caídos e espalhados pelo chão, prejudica a durabilidade e pode também gerar aborrecimento aos pais, que têm de dispor de tempo para organizar ou repor lápis quebrados, pois além do tradicional estojo, dificilmente o mercado dispõe de novas alternativas, práticas e lúdicas, que estimulem o uso e mantenham a organização da casa. Na internet, encontram-se ideias handmade, oriundas dos próprios familiares, que de maneira artesanal, iniciam o desenvolvimento do produto, a fim de atender a demanda que presenciam. Sendo assim, levanta-se a seguinte questão de pesquisa: como transformar a ideia de um brinquedo organizador artesanal em um produto lúdico, funcional e inclusivo?

Este estudo tem como objetivo geral transformar um brinquedo organizador de lápisde-cor artesanal em um produto lúdico, funcional e inclusivo. Os seus objetivos específicos referem-se ao uso das etapas e ferramentas do Processo de Desenvolvimento do Produto (PDP) para a geração de um protótipo virtual detalhado, coleta de feedbacks e análise de falhas. O trabalho delimita-se à fase de geração, com as fases do projeto informacional, conceitual e detalhado da abordagem de Rozenfeld et al., (2006).

\section{METODOLOGIA}

Para a execução, utilizou-se o método tradicional de desenvolvimento de produto, com fases e ferramentas baseadas nas fases de projeto informacional, conceitual e detalhado de Rozenfeld et al. (2006), também corroborando com a Metodologia para o Desenvolvimento de Brinquedos (BEINLICH, 2017). O trabalho permite o acompanhamento do PDP do brinquedo, característica de outros estudos de, como: A Gestão do Design na Indústria de Brinquedos (FERNANDES, 2015) e Contribuições do Design de Produto e Usabilidade no Projeto de Brinquedos: um Estudo Focado na Criança com Deficiência Visual (SILVA, 2013).

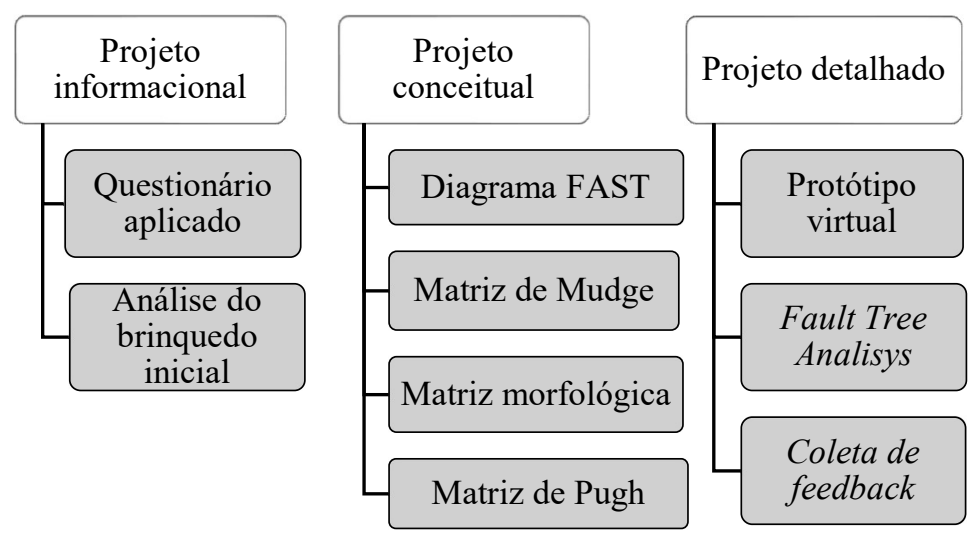

FIGURA 1 - Etapas do método de trabalho. Fonte: baseado em Rozenfeld at al (2006) 
O mapeamento inicial com os principais consumidores tornou possível a elaboração de um roteiro de questões (Figura 2) para pesquisa de campo direcionada. O roteiro busca fraquezas e fortalezas, requisitos buscados no momento da aquisição de brinquedos, e, obtenção depoimentos que esclareceram as primeiras impressões acerca do modelo inicial. Foram incluídas questões referentes aos 4Ps do marketing. As questões foram de caráter aberto, múltipla-escolha e de escala de avaliação, sendo o questionário do tipo estruturado não disfarçado, aplicado on-line, dividido em três seções.

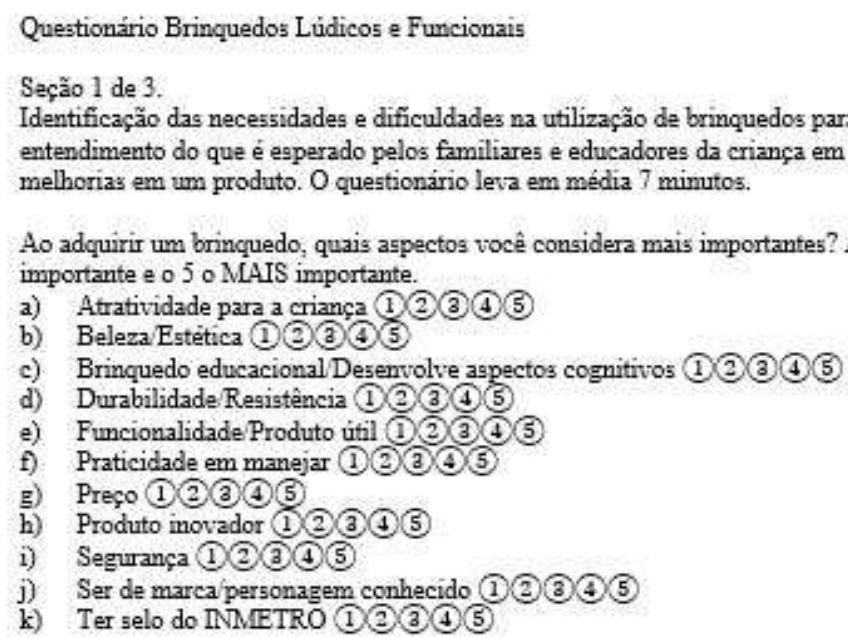

Onde vocè costuma adquirir os brinquedos? (Questào de múltipla-escolha) - Através de conhecidos/venda porta em porta | Feiras de produtos artesanais | Intemet | Lojas especializadas em artigos infantis | Lojas de produtos diversos | Shopping

Quanto você costuma investir ao comprar brinquedos? Até RS50| Entre R\$50 e R\$100 | Acima de R\$100

Qual o seu nivel de interesge por brinquedos artesanais e industrializados? Sendo 1 POUCO interesse e 5 MUTTO interesse. Artesanais (1) (2) (3)(4)(5) | Industrializados (1) (2) (3) (4) (5)

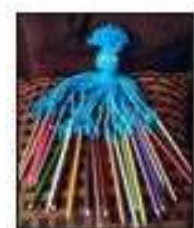

Seçào 2 de 3.

Analise de um brinquedo: 0 objetivo é analisar como um brinquedo feito em casa pode ser útil e funcional no dia-a-dia da criança e quais aspectos podem ser melhorados para que o brinquedo seja comercializado. A imagem ao lado retrata um produto artesanal com funçōes de gegurar/organizar lápis de cor e ser atrativo para crianças.

Cite pelo menos duas impressóes que o brinquedo the causa inicialmente:

Quais pontos você vê no produto que poderiam ser melhorados para comercialização e adaptação no dia-a-dia de uma criança?

Avalie quanto você considera que o brinquedo seria útil nos aspectos, sendo I POUCO útil e $5 \mathrm{MUTTO}$ útil. Melhorar a orgamização da criança (1) (2) (3)(4) (5) | Motivar para usar os lapis (1)(2)(3) (4) (5) | Entreter e divertir a criança (1) (2) (3) (4) (5)

Quando você estaria disposto a pagar pelo brinquedo da imagem acima? Qual o seu nivel de interesse no brinquedo da imagem? Sendo 1 POUCO interesse e 5 MUITO interesse.

Seção 3 de 3. - Questões para identificação do perfil.

Qual o geu gênero? Feminino | Masculino | Não desejo informar

Qual a sua idade? Até 24 anos | Entre 25 e 34 anos | Entre 35 e 44 anos | Entre 45 e 55 anos | Acima de 55 Em qual estado você mora?

Qual a sua relação com crianças? Tenho filhos | Tenho crianças na familia | Trabalho com crianças | Convivo com crianças de amigos

FIGURA 2 - Questionário ao público-alvo. Fonte: elaborado pela autora 
O resultado é expresso por gráficos, análises estatísticas, nuvem de palavras e ranqueamento dos requisitos. Buscou-se o direcionamento das informações adquiridas, unindo aspectos com melhor ranqueamento aos pontos de melhoria obtidos, tornando o processo mais abrangente as necessidades particulares de cada respondente, com sugestões referentes ao uso do brinquedo para crianças típicas e neuro-atípicas.

Cria-se o diagrama FAST (Function Analysis System Technique), composto das funções integradas de forma lógica, possibilitando o entendimento das relações, e o objetivo das funções primárias, secundárias e terciárias. São usadas três perguntas: "Por que?" "Como?" e "Quando?”. Uma função ao lado direito de outra no diagrama explicita como a função anterior ocorre, uma função à esquerda representa o porquê da ocorrência da função posterior, funções colocadas acima ou abaixo representam o quando (MASSARANI, 2007).

O Diagrama de Mudge compara funções, ordenando-as por relevância, na primeira coluna analisa-se a relevância da função $\mathrm{A}$ em relação à $\mathrm{B}$, e assim sucessivamente, com pesos de importância, gerando as relevância em relação ao total (SCHUSTER et al., 2015).

A análise morfológica provém da formulação do problema e parâmetros do conceito inicial, sendo uma técnica generativa, combinatória e criativa, possibilitando a visualização e exame de todas as possíveis soluções (ORTIZ, 2014). Identifica-se um conjunto de funções essenciais, cujas soluções geram combinações, incluindo variações de soluções já existentes ou inovadoras.

A Matriz de Pugh avalia a importância relativa de alternativas quanto à atributos qualitativos e quantitativos, com pesos. Escolhe-se uma concepção referência e utiliza-se para comparação entre outras. Determina-se qual é melhor, pior ou igual à referência com múltiplos critérios, formando um escore final (BURGE, 2009).

No projeto detalhado, realiza-se a elaboração de um protótipo, com as especificações desejadas para análise, comparando o virtual com o artesanal (Figura 2). A ferramenta Blender gera um protótipo com características do produto definitivo. Riscos de erros diminuem e chances de correção de falhas otimizam custos e tempo. A prototipação possibilita uma maior acuracidade com a realidade (XU; ABOURIZK, 1999).

A Fault Tree Analisys possibilita a análise de falhas com a visualização de causas primárias, seguindo um "evento-topo", com hipótese ou situação real, estabelecendo relações lógicas de causa. É utilizada para análise global, com mais conhecimento do funcionamento e dos mecanismos de falhas (SAKURADA, 2001).

Uma pesquisa foi aplicada com um psicóloga, especializada em psicopedagogia, para 
obtenção de feedback do PDP: adaptação do produto, pontos de falhas, sugestões de melhorias, questionamentos referentes ao atendimento dos pontos propostos e à integração com a realidade de crianças típicas e atípicas. Foram enviados os requisitos, objetivos do trabalho e a imagem do protótipo desenvolvido.

\section{RESULTADOS E DISCUSSÃO}

O questionário aplicado (Figura 2) teve adesão de 172 pessoas correlacionadas a crianças entre as idades de 2 a 8 anos, com duração média de 7 minutos. A amostra teve predominância do sexo feminino, 146 mulheres $(84,9 \%)$ e 26 homens $(15,1 \%)$. Majoritariamente, os respondentes vivem no Rio Grande do Sul $(65,1 \%)$. A principal faixa de idade está entre 35 e 44 anos (35,5\%), seguida da faixa etária entre 25 e 34 anos (29,7\%) e até $24 \operatorname{anos}(14,5 \%) .106$ dos participantes tem filhos (61,6\%), 28 tem crianças na família (16,3\%), 25 trabalham com crianças $(14,5 \%), 11$ convivem com crianças de amigos $(6,4 \%)$ e 2 não convivem com crianças $(1,2 \%)$.

$\mathrm{Na}$ análise da Figura 2, os participantes expressaram as suas primeiras impressões e sugestões de melhoria do brinquedo inicial. Os dados foram refinados para a geração de uma nuvem de palavras, as palavras de maior tamanho foram as mais citadas. Na nuvem foram usadas palavras que se repetiram pelo menos 5 vezes, ilustrando as principais impressões ao brinquedo. Referente as sugestões de melhoria para o produto, obteve-se 143 respostas, utilizadas para a gerações de requisitos posteriormente.

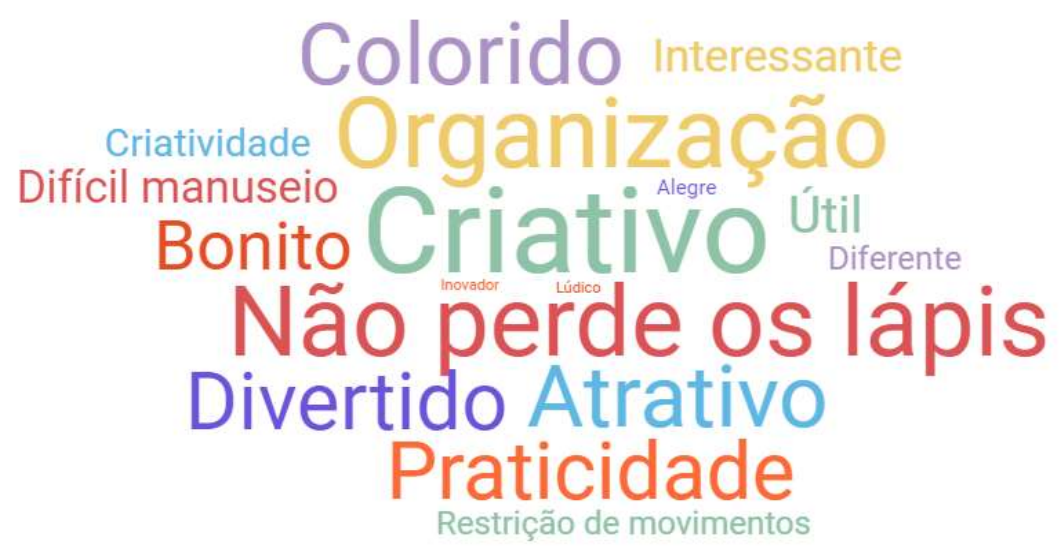

FIGURA 3 - Nuvem de palavras. Fonte: Elaborado pela autora (2020)

A Figura 4 expressa a porcentagem que os respondentes acreditam que o brinquedo tem relevância diante dos aspectos: melhora da organização da criança, motivação para usar os lápis e entretenimento e diversão da criança. O resultado mais expressivo foi em relação a melhora da organização da criança $(83 \%)$, e, todos os resultados foram superiores à $75 \%$. 


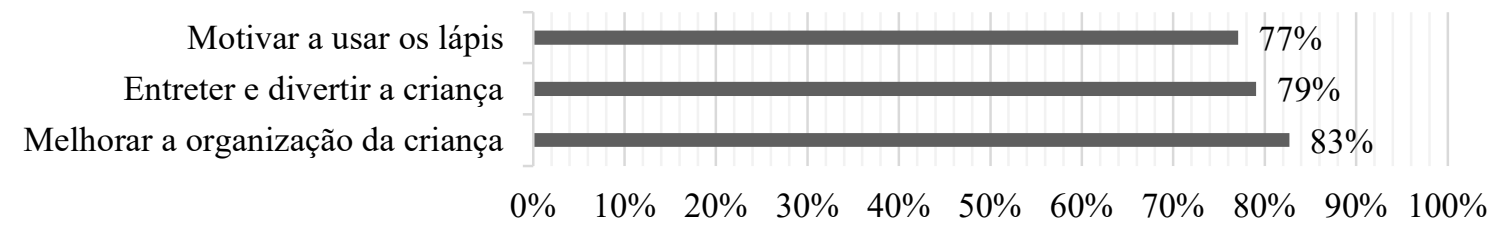

FIGURA 4 - Quanto o brinquedo pode ser útil para... Fonte: Elaborado pela autora (2020)

Identificou-se que o local de maior procura de brinquedos são lojas especializadas em artigos infantis (76,7\%), seguida da internet (50,6\%) e de lojas de artigos diversos (45,9\%). A aderência às feiras de produtos artesanais foi baixa, locais de venda mais relacionadas ao brinquedo inicial (Figura 2). Os resultados são demostrados na Figura 5.

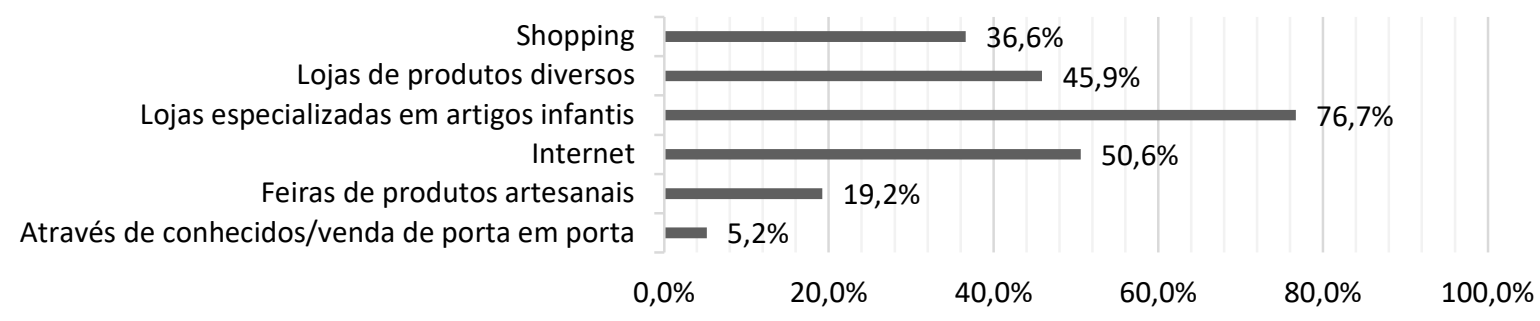

FIGURA 5 - Praça onde os brinquedos são adquiridos frequentemente. Fonte: Elaborado pela autora (2020)

$63,4 \%$ dos respondentes costumam investir entre $\mathrm{R} \$ 50,00$ e $\mathrm{R} \$ 100,0,22,1 \%$ costumam investir acima de $\mathrm{R} \$ 100,00$ e 14,5\% investem até $\mathrm{R} \$ 50,00$. O valor que os respondentes investiriam no brinquedo da Figura 2 foi considerado inconclusivo, algumas pessoas responderam considerando a compra do brinquedo com os lápis-de-cor inclusos, e outras pessoas considerarem apenas o polvo. O valor médio foi de $\mathrm{R} \$ 30,69$.

Os aspectos mais relevantes na escolha são apresentados em um ranking, com a melhor avaliação no topo e a menor abaixo - Figura 6. A questão continha uma escala de 1 a 5 , sendo o 1 considerado menos relevante e o 5 considerado o mais relevante, e evidenciou a importância dada pelos respondentes à segurança, ao desenvolvimento de aspectos cognitivos e a atratividade para a criança.

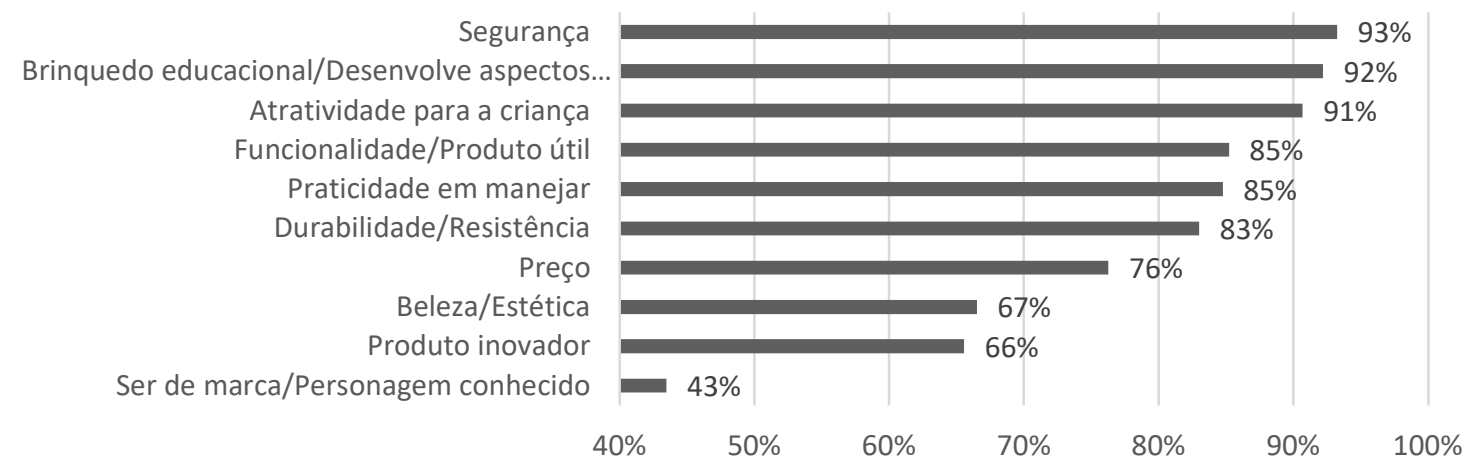

FIGURA 6 - Ranking aspectos relevantes 
Os principais requisitos buscados no processo de desenvolvimento de um brinquedo: Oferecer segurança à criança; Desenvolver aspectos cognitivos; Ser atrativo para a criança; Oferecer praticidade durante o uso; Não restringir os movimentos da criança; Material resistente; Possibilidade de fixar o brinquedo; Fixar os lápis de maneira que não sejam extraviados ou quebrados.

O Diagrama FAST (Figura 7) expressa as principais funções do brinquedo, permitindo o desdobramento da função principal, de organizar os lápis-de-cor, em funções primárias, secundárias e terciárias, identificando as funções de valor a serem exploradas.

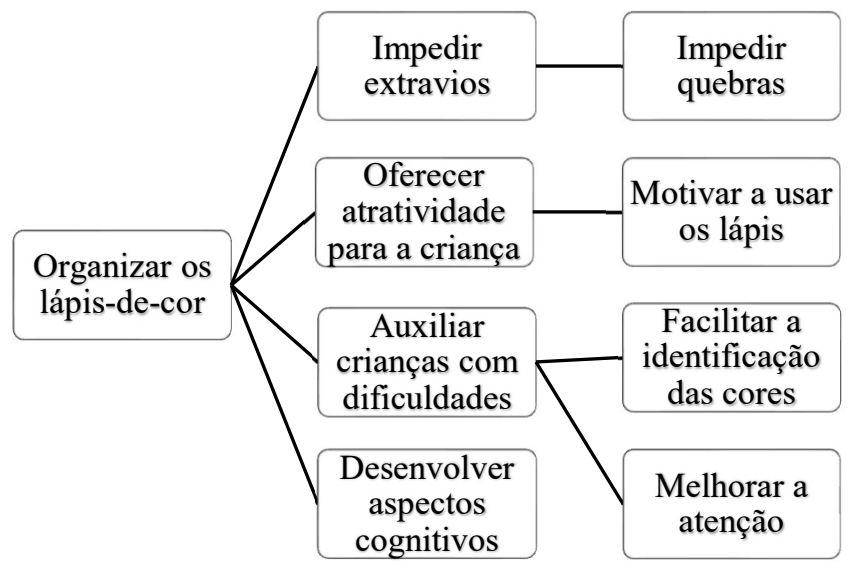

FIGURA 7 - Diagrama FAST. Fonte: Elaborado pela autora (2020)

Com a Matriz de Mudge, as funções secundárias foram analisadas para definição dos níveis de relevância e pesos totais. Impedir extravios e auxiliar crianças com dificuldades são as funções com maiores porcentagens - cada uma com 33,33\% -, conforme Figura 8, consideradas as funções secundárias mais relevantes.

\begin{tabular}{|c|c|}
\hline Peso & Descrição \\
\hline 1 & Um pouco mais importante \\
\hline 2 & Moderadamente mais importante \\
\hline 3 & Muito mais importante \\
\hline
\end{tabular}

\begin{tabular}{|c|c|}
\hline A & Impedir extravios \\
\hline B & Oferecer atratividade para a criança \\
\hline C & Auxiliar crianças com dificuldades \\
\hline D & Desenvolver aspectos cognitivos \\
\hline
\end{tabular}

\begin{tabular}{|c|c|c|c|c|c|}
\hline $\mathrm{A}$ & B & $\mathrm{C}$ & $\mathrm{D}$ & TOTAL & $\%$ \\
\hline \multirow[t]{5}{*}{$\mathrm{A}$} & A1 & $\mathrm{C} 1$ & $\mathrm{~A} 1$ & 2 & 33,33 \\
\hline & $\mathrm{B}$ & $\mathrm{C} 1$ & B1 & 1 & 16,67 \\
\hline & & $\mathrm{C}$ & D1 & 2 & 33,33 \\
\hline & & & $\mathrm{D}$ & 1 & 16,67 \\
\hline & & & & 6 & 100 \\
\hline
\end{tabular}

FIGURA 8 - Matriz de Mudge. Fonte: Elaborado pela autora (2020).

Utilizando os principais requisitos buscados no processo de desenvolvimento do brinquedo, em conjunto com as matrizes de relevância, aplicou-se o método morfológico, buscando soluções de melhorias com base no brinquedo inicial, de maneira estruturada. A matriz morfológica (Figura 9) apresenta as opções priorizadas circuladas. 


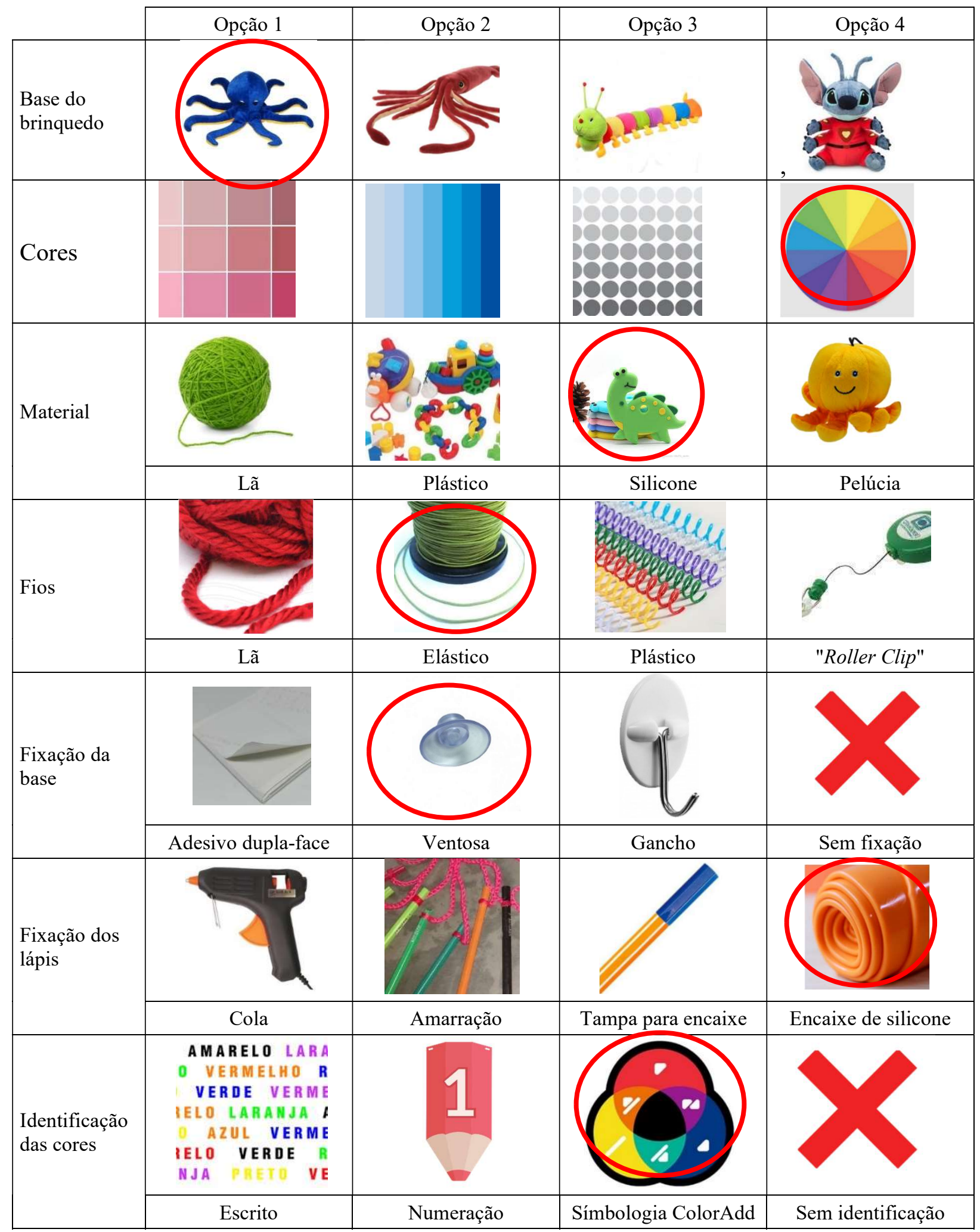

FIGURA 9 - Matriz Morfológica. Fonte: Elaborado pela autora (2020)

Considerando as respostas do questionário, a opção 1 foi escolhida para a base do brinquedo, mantendo o polvo do modelo inicial, explicitando um "antes e depois" do brinquedo, considera-se que o formato pode ser alterado posteriormente. As cores do brinquedo escolhidas são cores vivas e vibrantes, sendo atrativo para crianças. 
Quanto ao material da base, foi escolhido o silicone, com vantagens de facilidade e segurança, pois é lavável e macio ao toque para crianças. Os tentáculos, inicialmente de lã, são substituídos por elástico, de forma que os movimentos da criança não sejam restringidos e tenha maior resistência. Optou-se por fixa-lo, de forma que ao usar um lápis, não aja movimento do resto do brinquedo, a opção ventosa foi escolhida, possibilitando a mobilidade de lugar.

Em conversa com um designer de produto, gerou-se ideias para a fixação dos lápis no brinquedo. É necessário que seja possível a remoção dos lápis-de-cor quando desejado, mas que não exista mobilidade durante o uso, impedindo extravios. Optou-se por um encaixe de material flexível de silicone, unido a um imã em seu interior, para fixação do lápis.

Para facilitar a identificação das cores, a opção 3 foi escolhida, inserindo símbolos do ColorAdd para crianças daltônicas, chamada "linguagem das cores", considerado o código universal para daltônicos, permite que a conjugação de 5 símbolos básicos - cada um correspondente a uma cor - represente todas as cores existentes de forma combinada.

Com os desdobramentos gerados, foram criados dois conceitos para comparação com o conceito referência (Figura 2), analisando as características desejadas pelos usuários e critérios definidos pela autora, com pesos relativos. O conceito A conta com feições, elástico longo, múltiplas ventosas, simbologia no brinquedo e lápis separados do brinquedo. O conceito $\mathrm{B}$ tem elásticos médios, lápis juntos do brinquedo, simbologia nos lápis, uma única ventosa centralizada e suporte para pendurar. O conceito A obteve pontuação total melhor com base nos critérios estabelecidos na Matriz de Pugh.

\begin{tabular}{|l|l|c|c|c|c|}
\hline \multicolumn{2}{|c|}{ Conceito A } & \multicolumn{3}{c|}{ Conceito B } \\
\hline
\end{tabular}

FIGURA 10 - Conceitos A e B e Matriz Pugh. Fonte: Elaborado pela autora (2020) 
Com a avaliação dos conceitos, tornou-se possível a visualização dos fatores mais relevantes a serem considerados, selecionando os aspectos para a fase de criação do protótipo virtual do modelo proposto para o projeto detalhado (Figura 11).

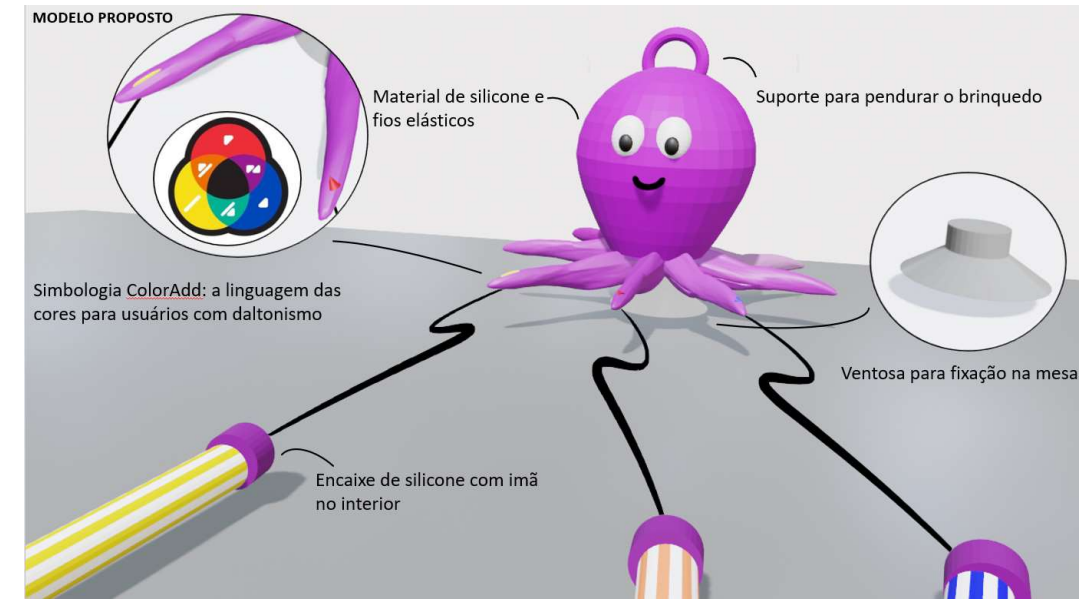

FIGURA 11 - Modelo Proposto. Fonte: Elaborado pela autora (2020)

O modelo conta com medidas de $15 \mathrm{~cm}$ de altura e $18 \mathrm{~cm}$ de diâmetro (Figura 12), além de um elástico com $35 \mathrm{~cm}$ de comprimento, permitindo a mobilidade da mão da criança sem restrições em uma superfície completa de uma folha A4. Reforça-se a possibilidade de variação no número de tentáculos, sendo oito o número do polvo, que pode ser adaptado para variantes de seis, números comumente encontrados em caixas de lápis-de-cor.

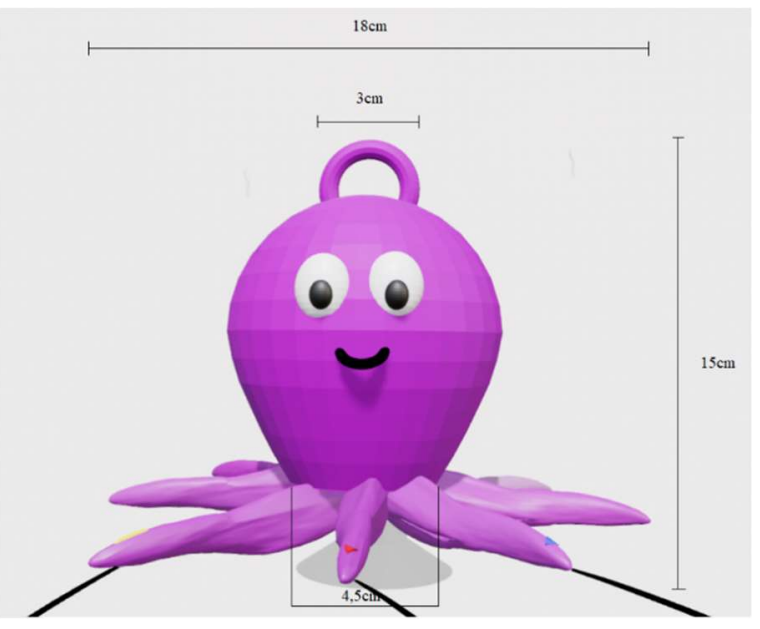

FIGURA 12 - Medidas. Fonte: Elaborado pela autora (2020)

As características de feições foram mantidas, gerando atratividade à criança, bem como o uso de cores vibrantes, sendo roxo, uma cor não associada entre sexos e que remete a sentimentos de felicidade (DIAS; 2009). Há um suporte na parte superior, permitindo que seja pendurado quando não estiver em uso.

A ventosa foi acoplada na parte inferior (Figura 13), possibilitando fixação do objeto na mesa e evitando que todos os lápis sejam movidos durante o uso, fato que ocorria no brinquedo 
inicial. A proposta é de lápis-de-cor separados do brinquedo, podendo ser acoplados por uma tampa de silicone aderente e dentro da mesma, determina-se o uso de imãs, a serem colados nos lápis-de-cor, possibilitando um encaixe livre de escapes para o manuseio e tornando possível que o usuário use os próprios lápis. $\mathrm{O}$ encaixe tem interior compatível com lápis de diferentes formas devido à adaptabilidade do silicone e aos diâmetros semelhantes, com cerca de $7 \mathrm{~mm}$.

A simbologia ColorAdd (também na Figura 13) foi inserida nos tentáculos do polvo, retratada com as cores respectivas à cada um dos símbolos, facilitando a identificação para usuários que não tenham daltonismo e que auxiliam as crianças no conhecimento da simbologia.

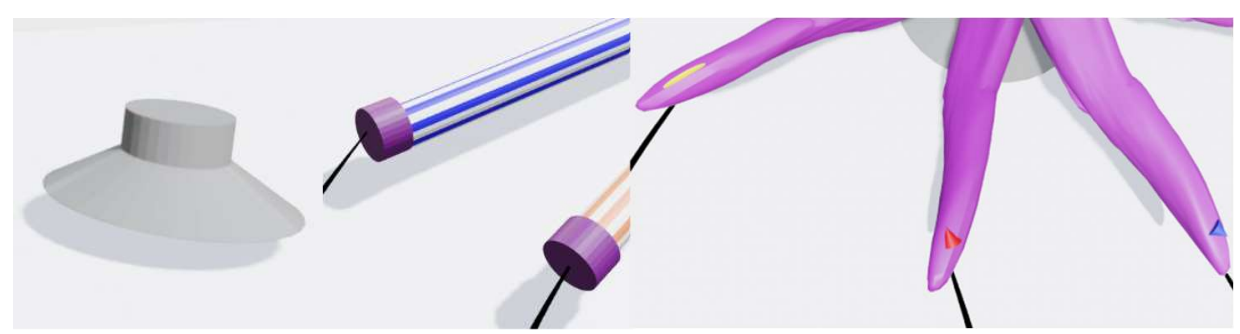

FIGURA 13 - Detalhes da ventoso e ColorAdd. Fonte: Elaborado pela autora (2020)

Na FTA, utilizou-se a hipótese da ocorrência da falha não-desejada da não-fixação dos lápis, com operações lógicas para construção da árvore (Figura 14). Os desdobramentos demonstram que o evento pode ocorrer devido à má utilização do usuário, ao uso de material de baixa resistência, as especificações incorretas ou falha. Reforça-se a necessidade de testes de utilização e resistência, é de extrema importância que o produto apresente qualidade e atenda aos requisitos especificados, não apresentando assim o evento não-desejado.

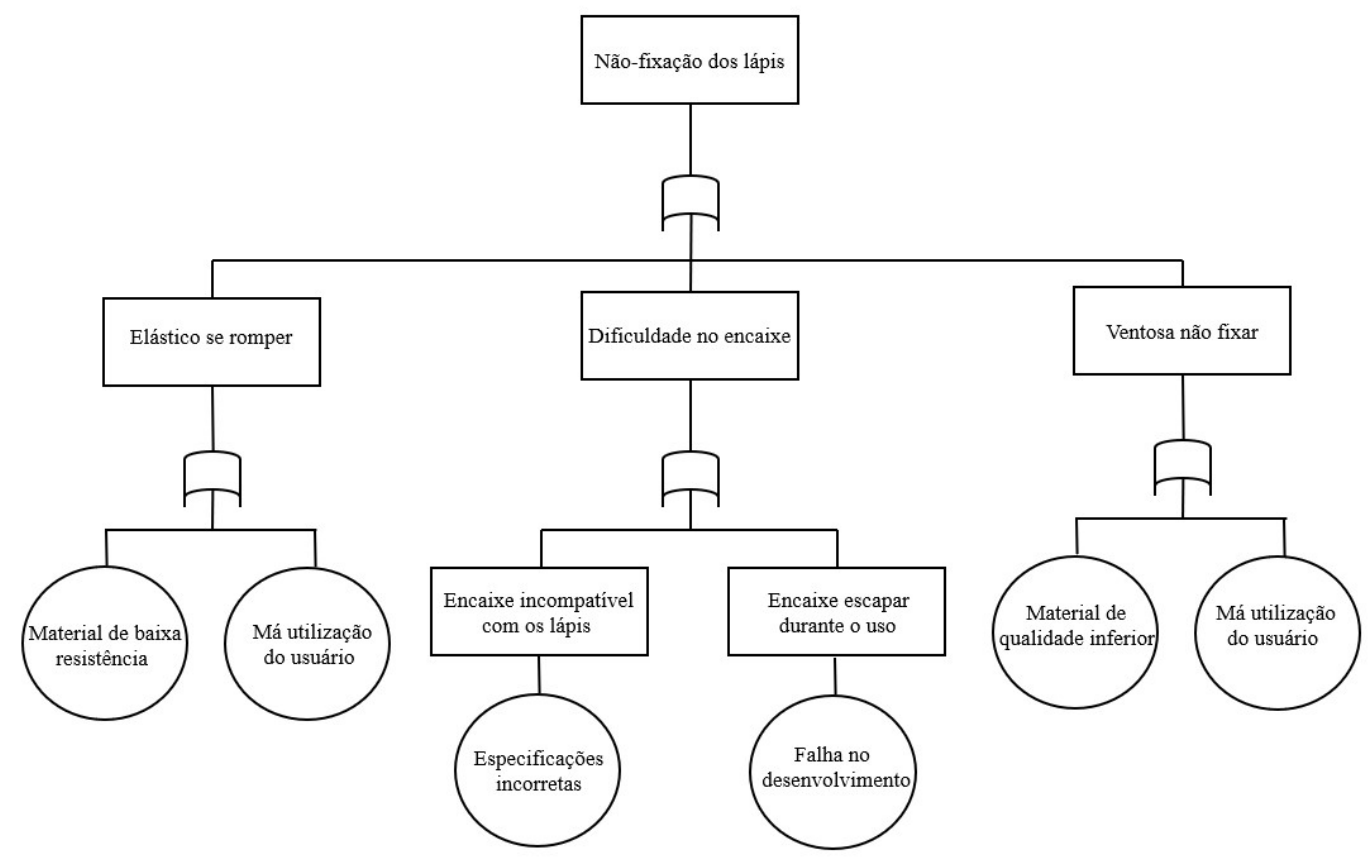

FIGURA 14 - FTA. Fonte: Elaborado pela autora (2020) 
O modelo proposto (Figura 11) foi encaminhado para uma psicóloga com especialização em psicopedagogia, a fim de avaliar os aspectos de desenvolvimento cognitivo, inclusão e melhorias do brinquedo, gerando o seguinte comentário: "É um brinquedo que estimula aspectos cognitivos, como o motor, o perceptivo, a coordenação viso-motora, dentre outros, possibilitando o aprendizado das cores e a brincadeira com o polvo. Através da ludicidade, ele proporciona a melhor organização do material escolar, principalmente no caso de crianças especiais, servindo como um incentivo para o momento das tarefas. Para o caso de crianças com necessidades especiais, como o Transtorno do Espectro Autista (TEA), poderiam ser exploradas outras formas de se trabalhar, com formas e texturas diferentes, como por exemplo, estimulantes do tato da criança (algodão, textura de lixa, superfície lisa) ou objetos diferentes ligados ao polvo".

Duas profissionais da área de design do produto também fizeram sugestões referentes aos pontos de melhoria ou possíveis modificações futuras no produto, sendo elas a utilização de material emborrachado no brinquedo, a utilização de lápis com maior diâmetro - ideal para crianças pequenas devido a facilidade na pega - e a possibilidade de trabalhar no produto de forma que ele se tornasse um brinquedo-estojo, onde os lápis pudessem ser guardados dentro do seu interior.

Os feedbacks demonstram que o produto permanece aberto para melhorias, apresentando resultados satisfatórios em relação ao inicial e possibilidade de maiores desdobramentos para alcance mais abrangente, como com a utilização de funções específicas para crianças do espectro autista, ou, com desdobramentos, como no caso da sugestão de um estojo-brinquedo.

\section{CONCLUSÃ̃o}

O presente trabalho respondeu à questão inicial de pesquisa, referente à proposta de transformar um brinquedo artesanal em um produto lúdico, funcional e inclusivo, com as ferramentas adaptadas de Rozenfeld et al. (2006) na construção efetiva das etapas projetuais, de modo que os objetivos gerais pudessem ser atingidos, bem como os seus objetivos específicos, com a criação do protótipo virtual de modelo detalhado, coleta de feedback e a análise de falhas.

Os resultados positivos do brinquedo de modelo inicial, referentes à motivação ao usar os lápis, entreter e divertir a criança e melhorar a organização da criança, demonstram uma boa aderência, que durante a construção do trabalho, teve as suas fraquezas adaptadas e melhoradas, 
tornando-se um produto mais robusto e com maior potencial no mercado. O trabalho diferenciase por abordar aspectos inclusivos dentro do PDP, expandindo o conhecimento e contribuindo de forma a tornar mais abrangentes as ferramentas pré-existentes na aplicação em produtos.

Ainda, as sugestões por parte de profissionais, possibilitaram a visualização de como o produto tem potencial de melhoria contínua, tornando-se mais abrangente principalmente para crianças neuro-atípicas, e, de diferentes funcionalidades, como a proposta de um brinquedoestojo. $\mathrm{O}$ brinquedo original pode também ser adaptado de diferentes formas, como com um número diferente de tentáculos, para fixar mais ou menos lápis-de-cor, ou de um modelo diferente de objeto, podendo o polvo ser substituído por uma centopeia, haver mudança na cor, dentre outros.

Salienta-se a necessidade de uma embalagem adequada para especificar os diferenciais de acessibilidade do brinquedo, exemplificando mais detalhes do ColorAdd, aplicado para a identificação das cores por crianças com daltonismo. Por fim, reforça-se que a criação de um protótipo funcional físico do modelo proposto virtualmente é relevante para que mais resultados sejam obtidos e seja melhor-analisada a integração da criança com o brinquedo, suas escalas e suas funções, para o foco na experiência do usuário, na usabilidade e na ergonomia, bem como para a definição dos custos do produto e detalhes do processo de manufatura.

\section{AGRADECIMENTOS}

Agradeço à minha família e amigos, por todo o suporte e carinho, e aos meus professores, por todo o conhecimento compartilhado.

\section{REFERÊNCIAS}

ASSOCIAÇÃO BRASILEIRA DOS FABRICANTES DE BRINQUEDOS. Setor de brinquedos encerra 2018 com 7,5\% de crescimento. Abr, 2019. $<$ https://abrin.com.br/2019/04/02/setor-de-brinquedos-encerra-2018-com75-de-crescimento/> Acessado em: 16 de setembro de 2020.

ASSOCIAÇÃO BRASILEIRA DOS FABRICANTES DE BRINQUEDOS. Relatório anual 2019. São Paulo, 2020. <https://www.fadc.org.br/sites/default/files/2020-04/relatorio-anual-FADC-2019.pdf> Acessado em: 22 de outubro de 2020 .

BAXTER, Mike. Projeto de Produto: guia prático para o design de novos produtos. $3^{\text {a }}$ ed. São Paulo: Edgard Blucher, 2011.

BEINLICH, Simone. Metodologia para o desenvolvimento de brinquedos. Dissertação (Mestrado em Engenharia de Produção) - Universidade Tecnológica Federal do Paraná, PPGEP/UTFPR, Ponta Grossa, 2017.

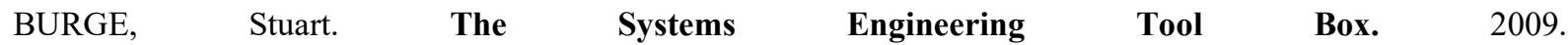

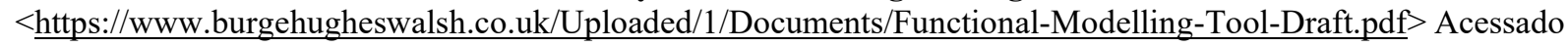


em:18 de novembro 2020.

CRUZ, Vanessa Carla Duarte Santos. Projeto e desenvolvimento de uma ajuda técnica numa perspectiva de Design Inclusivo. 2010. Dissertação (Mestrado em Design Industrial Tecnológico) - Universidade da Beira Interior, Covilhã, 2010.

FERNANDES, Rodrigo Queiroz Kühni. A Gestão do Design na indústria de brinquedos. Dissertação (Mestrado em Design) - Universidade Federal de Pernambuco, Recife, 2015.

INSTITUTO NACIONAL DE ESTUDOS E PESQUISAS EDUCACIONAIS ANÍSIO TEIXEIRA (INEP). Resultados preliminares do Censo Escolar (rede estaduais e municipais). Brasília, 2020. Disponível em:

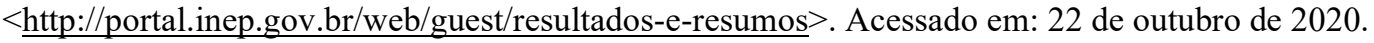

MASSARANI, Marcelo. Redução de custos através da engenharia de valor. São Paulo, 2007.

ORTIZ, Felipe Chibás. Métodos de Criatividade para Gerir a Comunicação. Comunicação \& Inovação, PPGCOM/USCS, Santa Cruz, v. 15, 2014.

PEREIRA, Alessandra Keyth; MAIA, Edmara Bazoni Soares; BORBA, Regina Issuzu Hirooka de; RIBEIRO, Circéa Amália. O brincar da criança com transtorno de déficit de atenção e hiperatividade. São Caetano do Sul, 2014.

ROZENFELD, Henrique; FORCELLINE, Fernando Antônio; AMARAL, Daniel Capaldo; TOLEDO, José Carlos; SILVA, Sérgio Luis da; ALLIPRANDINI, Dário Henrique; SCALICE, Régis Kovacs. Gestão de desenvolvimento de produtos: uma referência para a melhoria do processo. São Paulo: Saraiva, 2006.

SAKURADA, Eduardo Yuji. As técnicas de Análise dos Modos de Falhas e seus Efeitos e Análise da Arvore de Falhas no desenvolvimento e na avaliação de produtor. Florianópolis, 2001.

SCHUSTER, Cristiano Henrique; SCHUSTER, Jean Jonathan; OLIVEIRA, Alexandre Silva. Aplicação do diagrama de Mudge e QFD utilizando como exemplo a hierarquização dos requisitos para um carro voador. Bauru, 2015.

SILVA, Roseane Santos. Contribuições Do Design De Produto E Usabilidade No Projeto De Brinquedos: Um Estudo Focado Na Criança Com Deficiência Visual. Porto Alegre, 2013.

SILVA, Roseane Santos; ROMANO, Fabiane Vieira; BATTISTEL, Amara Lúcia Holanda Tavares. Design de um produto de tecnologia assistiva voltado para auxílio da atividade de alimentação infantil. Design e Tecnologia, v. 2, Porto Alegre, dez. 2012.

TENUTA, Adriane Ribeiro Andalo. Um olhar semiótico sobre as várias maneiras de desenhar um cubo. Bauru, 2005.

XU, Jianfei; ABOURIZK, Simaan. Product-based model representation for integrating 3D CAD with computer simulation. Canadá, 1999. 